\title{
Cônsules Honorários
}

\author{
Paulo Borba Casella \\ doutor em direito (USP), dess em direito do \\ comércio internacional (Univ. de Paris X), assistente do \\ Depto. de Direito Internacional (FADUSP)
}

RESUMO: A instituição consular mostra sua vitalidade pela permanência, não obstante as mudanças ocorridas ao longo do tempo. A crescente profissionalização levou à preponderância dos cônsules de carreira, mas é no cônsul honorário que se conservam os traços originais: o cidadão de prestígio, cuja atuação visa a proteção dos interesses e direitos dos seus nacionais.

RESUMÉ: L'institution consulaire nous montre sa vitalité par sa permanence, en dépit des changements au long du temps. La professionalisation qui s'accentue a abouti à la préponderance des consuls de carriere, mais c'est le consul honoraire qui conserve le mieux les traits originaux: le citoyen de prestige, dont l'actuation a pour but la protection des intérêts et des droits de ses nationaux.

\section{INTRODUÇÃO}

A instituição consular comprova sua vitalidade ao longo da História: a estabilidade e a permanência são as notas marcantes sob as múltiplas variaçōes que foram influenciando a forma, as características jurídicas, e o desempenho de seus protagonistas. Apesar da crescente profissionalização, que leva à preponderância, em número e em extensão, da atuação dos cônsules de carreira, ainda assim, os cônsules honorários permanecem e se renovam, em virtude das vantagens específicas que diferenciam os "consules electi" dos "consules missi” Na figura do cônsul honorário é que se podem encontrar, em sua plena extensão, as notas marcantes da figura histórica: o homem de prestígio, que se insere com destaque em determinado grupo social, no seio do qual, a ele compete zelar pelos interesses e pela integridade do ser e do ter dos nacionais do Estado que o nomeia.

Enquanto o cônsul de carreira constitui um fenômeno posterior, que acompanha com maior ou menor proximidade a estruturação de representaçōes 
diplomáticas de caráter permanente, iniciando-se no século XV e expandindose ao longo do século XVII, o cônsul honorário é um fenômeno mais antigo, cujas origens podemos encontrar na antiguidade, muito embora seja até certo ponto difícil ou mesmo arriscado tentar caracterizar o estrito caráter consular dos proxenoi ou dos prostate.

Apesar de uma estrita caracterização não ser, colocando a análise em ótica estritamente formal, configurável, já na vivência das cidades-estado da Hélade clássica, estas figuras apareciam e atuavam em moldes que caracterizam a atividade consular em todos os tempos e sob todas as suas formas.

\section{EVOLUÇĀO HISTÓRICA}

Um aperçu historique representa antes de tudo um esforço de compreensão: olhando o passado, fazemos um esforço para captar o quadro que já não mais existe, mas cuja totalidade pressentimos, auxiliados pela percepção do presente e partindo de realidade e dados isolados que conhecemos, para prosseguir almejando tentativa de entendimento maior, integrando o que conhecemos, para poder perceber mudanças e permanências.

Esta necessidade de conjugar em análise dados múltiplos, que se estendem ao longo do tempo, é fundamental ao abordarmos o instituto consular. Analisando a questão, exclama o Prof. Giusepe BISCOTTINI (La natura giurudica della fonzione consolare):

non v'e forse campo in cui piú chiara sia la necessitá di riferirsi al passato per intendere il presente e più palese sia il continuo divenire del diritto positivo.

Constatação que, desde logo, se nos impōe, é a da espantosa flexibilidade do instituto consular, que

costituice un mirabile esempio di addatamento degli strumenti giuridici alle diverse concezioni politiche dello Stato,

de forma tal, que nos vemos continuamente confrontados com processo de

adeguadamento dei mezzi al fine di tutelare gli interessi dei propri cittadini in territorio straniero

O instituto consular nos coloca em face de quadro variado, onde 
ad un unico nome corrispondono fonzioni

sostanzialmente diverse, non soltanto in differenti periodi storici, ma anche nella medesima epoca in diversi ambienti.

O surgimento da instituição consular decorreu da necessidade de proteger mercadores e navegadores que se deslocavam de sua cidade natal, de seu meio social habitual, para intervir e atuar e realizar negócios em outras localidades, reguladas por ordenamento distinto.

A necessidade de proteção se deveu à situação dos estrangeiros na antiguidade, em virtude do não reconhecimento do caráter de cidadão e da falta de amparo por parte dos órgãos e autoridades locais.

Nas cidades gregas foi tomando corpo o costume de nomear um protetor, o prostates, que atuava na qualidade de intermediário, nas relaçōes jurídicas e políticas entre o estrangeiro e o poder público do local onde atuava o representante.

Mais tarde surgem os proxenoi, escolhidos dentre os cidadãos da cidade, onde se fazia necessária a proteção, e cuja atuação era solicitada, encarregados de representar os estrangeiros em suas relações com os órgãos da cidade e da justiça local. $\mathrm{O}$ dever do proxenos consistia sobretudo em atuar, em nome do estrangeiro, perante tribunais, assembléias, agindo como testemunha na confecção de testamentos, regulamentando a sucessão de estrangeiros mortos sem deixar herdeiros, etc. (cf. Graham STUART, Le droit et la pratique diplomatique et consulaire, 1934, e Jaroslav ZOUREK, Le statut et les fonctions des consuls, 1962).

Como bem salienta o Prof. ZOUREK:

Les proxenes étaient déjà des agents officiels dont les fonctions ressemblent par plusieurs aspects à celles de nos consuls honoraires modernes.

Em Roma, em meados do terceiro século antes da era cristã, a instituição do praetor peregrinus, para decidir questōes envolvendo estrangeiros entre si, ou estrangeiros e cidadãos romanos, foi dado que impulsionou o jus gentium.

$\mathrm{Na}$ Idade média, podemos razoavelmente invocar certa semelhança no caso dos telonarii. O Código visigodo, do século VII A.D., comprova a existência de jurisdição especial, para decidir a respeito de controvérsias envolvendo mercadores estrangeiros, que eram julgados por seus próprios magistrados. 
O recrudescimento do comércio, em escala internacional, levou ao desenvolvimento de classe de magistrados, a quem competia julgar questōes concernentes ao comércio e a navegação: os assim chamados juízes-consules, consules mercadores, ou consules do mar, especialmente nas cidades do mundo mediterrâneo, enquanto na Europa do Norte, nas cidades que integravam a Liga Hanseática, por seu turno, vemos surgirem as figuras dos consules, proconsules, síndicos ou anciãos. Nessas cidades, os cônsules eram funcionários políticos e administrativos e não juízes.

Estes cônsules são os precursores das Cortes do Almirantado, e dos tribunais comerciais de nossos tempos.

Os cônsules municipais serviram de modelo a duas outras classes de magistrados: os cônsules do mar e os cônsules de além mar. Os cônsules do mar eram juízes que atuavam a bordo dos navios, e a quem competia zelar pela manutenção da ordem durante as viagens. Também visando a proteção dos direitos dos mercadores, surgiram os cônsules de além-mar, que eram eleitos pelos membros da comunidade de mercadores de determinada cidade. Posteriormente, foi se ampliando o âmbito de atuação, e tornou-se praxe nomear tais cônsules e enviá-los ao exterior.

Com o passar do tempo, e concomitantemente com o fortalecimento do poder central dos Estados modernos, os cônsules foram sendo progressivamente destituídos de suas prerrogativas jurisdicionais. O exercício de jurisdição civil e penal passou a ser prerrogativa do Estado.

Outra limitação à atuação dos cônsules se deveu à aparição das missões diplomáticas permanentes no século $\mathrm{XV}$, e sua ampliação a partir do século XVII, privando os cônsules de seu estatuto diplomático. Como frisa Jaroslav ZOUREK:

A partir de la fin du XVII eme siècle, les consuls ont pour mission de protéger les intérêts des ressortissants de l'État d'envoi dans le domaine du commerce, de l'industrie et de la navigation.

A evolução histórica mostra que, anteriormente, a proteção do comércio e da navegação constituía o elemento essencial das funções consulares, enquanto, em nossos dias, o estabelecimento de missōes diplomáticas permanentes e a criação de representações comerciais, levou os consulados a concentrarem suas atividades em funçōes de ordem administrativa (ZOUREK).

\section{A FUNÇĀO CONSULAR}

l'istituto consolare si presenta perciò come una specie di caleidoscopio, in cui le imagini si compongo- 
no e mutano nelle forme più diverse al più lieve spostamento. E, come nel caleidoscopio le figure che noi osserviamo son determinate da frammenti di diverso colore, cosi nella missione del console si intersecano le diverse fonzioni di cui si è detto $e$ spesso chi si accinge all'analisi resta attrato or da questa or da quella componente, ma perde di vista l'armonia della composizione. (G. BISCOTTINI)

A função consular congrega vasta gama de atividades, do conjunto das quais podemos depreender uma linha mestra: zelar pelos interesses do povo, em nome do qual ele é nomeado, no exterior, ou mais especificamente na circunscrição consular onde o cônsul exerce a sua atividade. Muito embora formalmente discutível o emprego do termo povo neste contexto, vale a pena insistir neste ponto, para frisar a diferença de ótica e de finalidade, que distingue o diplomata do cônsul. Enquanto o primeiro é antes de tudo um representante do Estado, cuja atividade fundamental consiste em manter relações entre o Estado que nomeia e o Estado onde atua o representante, o papel do cônsul, por seu turno, se concentra no sentido de tutelar interesses de seus concidadãos.

A atividade e o papel dos cônsules refletem a base histórica do instituto: a função de tutela dos conacionais, tendo para tanto gozado da prerrogativa de agir de acordo com as leis pátrias em território estrangeiro.

Atribuição principal e específica da atividade consular, é a tutela dos interesses do Estado e de seus cidadãos.

A tutela consular tem como características, via de regra: ser preventiva e estar localizada. Seu caráter preventivo, configurado na medida em que tende a evitar violação do direito internacional por parte do Estado no qual o cônsul exerce a sua atividade, e seu caráter localizado, decorre do fato que a ação consular, não se dirige aos órgāos que determinam a linha geral de atuação política do Estado, mas a órgãos locais, aos quais compete determinar a linha de atuação em casos específicos. O Estado, que mantém relações consulares, tem a prerrogativa, amparada pelo direito internacional, de fazer valer as pretensōes dos indivíduos no terreno do direito interno. Este é aspecto fundamental da função consular, que explica a sua natureza e os seus limites, como lucidamente coloca o Prof. BISCOTTINI:

La nota saliente della fonzione consolare reside in ciò: nel tutelare interessi internazionali dello stato individuando gli organi interni presso cui conviene intervenire, per ottenere che i suori diritti siano rispettati; individuando le norme interne di cui conviene invocare l'osservanza; calibrando, cioè, le 
pretese internazionali all'ordinamento interno dello Stato ospite.

A análise da natureza jurídica da função consular nos leva a constatar que o cônsul é simultaneamente um órgão das relaçōes internacionais, e órgão da administração pública que desempenha atividade no exterior, e, tanto um como o outro aspecto da função consular têm em vista a proteção dos interesses nacionais no exterior.

E tutto questo si riporta a considerare che la ragione prima dell'istituzione dei Consolati sta nella condizione di inferiorità in cui so trova lo straniero.

uma vez que,

lo straniero appare destinato a conservare la condizione di mero suddito e solo lo Stato a cui appartiene ed alla cui vita politica egli partecipa può assicurargli la protezione di cui ha bisogno.

\section{O CONSUL HONORÁRIO}

Si le consul est un fonctionnaire de l'Etat d'envoi et fait partie des services consulaires réguliers, après avoir été préparé pour cette carrière, et s'il est en fait soumis au pouvoir disciplinaire de l'État, il s'agit d'un consul de carrière, dans les autres cas d'un consul honoraire. (Jaroslav ZOUREK)

Em vista das atribuiçōes jurisdicionais dos cônsules, o exercício de suas atividades impunha o conhecimento do ordenamento jurídico do país ao qual pertenciam as partes litigantes, razão pela qual recaía normalmente sobre membro da corporação de mercadores e navegadores, para ser nomeado cônsul de além mar. Contudo, a possibilidade de nomear cônsul uma personagem influente da cidade sede de atuação apresentava algumas vantagens. Desta forma surgiu, no século XIII, uma nova categoria de cônsules (consules hospites), distinta dos outros cônsules de além mar.

No século XVIII, começa a ser utilizada a terminologia consules missi para designar os cônsules enviados, e consules electi para os cônsules eleitos no local. Mas, como frisa J. ZOUREK:

à ce moment-là, cette dénomination ne correspondait nullement à la distinction entre les 
consuls de carrière et les consuls honoraires, mais désignait uniquement le mode de nomination des consuls. A cette époque, un étranger pouvait être aussi bien um consul electus qu'n consul missus. (...) Qu'ils aient appartenu a l'une ou l'autre catégorie, les consuls continuaient en règle générale à exercer le commerce ou une autre occupation lucrative.

Não obstante a evolução e a profissionalização crescente das representações, alguns Estados, ao lado de cônsules de carreira, continuam, como no passado, a nomear cônsules honorários, radicados no local da sede de atuação, e via de regra, nacionais do Estado de residência.

Ces consuls sont choisis parmi les commerçants en vue, les banquiers, les avocats et ont le plus souvent la nationalité de l'État de résidence. On les appelle consuls honoraires.

Apesar de críticas que tem recebido, e de problemas que apresenta, a instituição dos cônsules honorários continua presente e vem sendo empregada por bom número de países, muito embora se possa perceber que o seu papel é hoje mais restrito que dantes.

A vitalidade da instituição dos cônsules honorários se deve a dois motivos: inicialmente porque os consulados honorários exigem volume de despesas muito mais reduzido do que os consulados regulares, possibilitando a criação e manutenção de rede de consulados mais extensa, e, em segundo lugar, porque esta instituição permite a nomeação como cônsules de pessoas radicadas no local, com conhecimento das condições autóctones possibilidades de contato muito maiores do que um cônsul de carreira pode normalmente ter.

Não obstante o estreitamento de sua utilização ou mesmo sua abolição por parte de alguns países, especialmente os países da Europa Oriental, a instituição dos cônsules honorários continua viva e presente, e desta forma integrando o direito consular.

A instituição de cônsules honorários é estritamente facultativa, tendo portanto cada Estado total liberdade para enviar ou receber cônsules honorários.

Muito embora o direito internacional não imponha restrições à atividade dos cônsules honorários, que, em princípio, poderiam exercer toda e qualquer função consular, na prática, a atividade de um consulado honorário é frequentemente mais restrita que a de um consulado normal. É o Estado que nomeia o 
cônsul honorário quem determina a extensão de suas funções. Como regra geral, os cônsules honorários não exercem funções reservadas aos funcionários do Estado acreditante, tais como funçōes cartorárias, administrativas e jurisdicionais.

Quanto aos privilégios e imunidade dos cônsules honorários, via de regra os consulados honorários não têm local consular reservado exclusivamente ao exercício das funções consulares, mas, apesar do local não ser utilizado exclusivamente para este fim específico, e apesar do tempo normalmente reduzido que um cônsul honorário dedica ao desempenho de suas funções consulares, os cônsules honorários são órgãos do Estado que os nomeia, e devem portanto estar respaldados pelos privilégios e imunidades indispensáveis ao exercício de suas tarefas.

Os privilégios e imunidades se dividem em dois grupos: privilégios e imunidades do consulado e privilégios e imunidades pessoais, visando garantir o eficaz desempenho das funções consulares.

No tocante aos privilégios e imunidades relativas aos locais consulares, existe consenso quanto ao direito de (a) colocar o pavilhão nacional e o escudo de armas do Estado acreditante na parte externa do edifício ou sobre a entrada dos locais onde são exercidas as funções consulares; (b) comunicação com outras autoridades do Estado acreditante, tanto no país, como no território do Estado acreditado; (c) se dirigir às autoridades do Estado acreditante; (d) exigir e receber pagamento pela prática de atos consulares; (e) imunidade fiscal. Em suma, como concentradamente expõe J. ZOUREK:

Il est égalemente reconnu que l'État de résidence, qui a consenti à recevoir le consul honoraire, est tenu de lui accorder toutes facilités pour l'accomplissement de ses fonctions.

Existe tendência no sentido de se reconhecer a inviolabilidade do local CONSULAR dirigido por um cônsul honorário, com a condição de ser este local destinado exclusivamente ao exercício de funções consulares. Reconhece-se igualmente, o direito à isenção fiscal dos locais consulares, bem como à inviolabilidade dos arquivos, documentos e da correspondência oficial do consulado, (ficando justificada a distinção entre correspondência oficial e correspondência particular quando o cônsul honorário exercer atividade privada de caráter lucrativo).

No tocante aos privilégios e imunidades pessoais, é preciso, sempre, ter em mente, que as funções do cônsul honorário são mais limitadas que as do cônsul de carreira, e, em razão, sobretudo, do fato que os cônsules honorários quase sempre exercem profissão privada de caráter lucrativo, reconhecendo, a 
prática dos Estados, privilégios e imunidades mais restritos aos cônsules honorários que aos cônsules de carreira. Não se nega, contudo, a necessidade de se reconhecer aos cônsules honorários a imunidade de jurisdição para os atos realizados no exercício de suas funções, tais como o direito de recusa de depoimento judicial com relação a fatos ligados ao exercício de suas funções, bem como a exibição de correspondência e documentos a eles relativos, a isenção alfandegária para objetos destinados a uso oficial, bem como a prerrogativa dos cônsules honorários de se comunicarem com o governo do Estado acreditando, bem como suas missões diplomáticas e consulares no Exterior.

Os cônsules honorários devem gozar dos privilégios e imunidades pessoais indispensáveis ao exercício de suas funçōes, entre os quais são normalmente reconhecidos os seguintes direitos: (a) proteção especial, que consiste essencialmente no dever de garantir a segurança pessoal do cônsul honorário, nos casos em que sua dignidade ou sua vida estejam sendo ameaçadas em virtude de sua posição oficial; (b) isenção de obrigações em matéria de registro de estrangeiros e autorização de residência; (c) isenção fiscal; (d) isenção de prestaçōes pessoais.

\section{A CONVENÇĀO DE VIENA DE 1963}

A Convenção de Viena sobre relações consulares, de abril de 1963 (aprovada pelo Decreto Legislativo no 6/1967, ratificada a 20.04.1967, depósito de ratificação a 11.05 , tendo entrado em vigor para o Brasil a 11.06.1967, promulgada pelo Decreto no 61.078, de 26.06.1967, D.O. de 28.06.1967, informa o Prof. Vicente Marotta RANGEL, Direito e relações internacionais), se insere no âmbito da obra de codificação do direito internacional ensejada pela O.N.U., nos termos do artigo 13, I, a, da Carta da Organização, almejando "promover cooperação internacional no terreno político e incentivar o desenvolvimento progressivo internacional e a sua codificação", foi firmada a Convenção de 1963, que constitui o documento normativo internacional mais importante na matéria.

Como acertadamente lembra o Prof. Guido SOARES:

Em muitos aspectos, os cônsules, lato sensu, guardam um paralelismo com os agentes diplomáticos: o caráter comum de agentes das relações exteriores do Estado, cuja função impõe ao Estado que os recebe, uma série de obrigaçōes de respeito à pessoa e atos que praticam. A regra ne impediatur legatio, que traduz o princípio de base para fundamentar as imunidades diplomáticas, se expressa na regra ne impediatur officium, quando transposta para as relaçōes consulares, e na sua essência, ambas expressam limites ao poder do 
Estado receptor, a fim de não turbar a cooperação entre os Estados. Contudo pelo fato de as relações consulares terem conteúdo distinto das diplomáticas, os privilégios e imunidades dos representantes consulares tem uma abrangência distinta. (Das imunidades de jurisdição e de execução, p. 48).

A Convenção de 1963 representou uma conquista, uma realização e um progresso.

Neste fundamental documento internacional ficam claramente delimitadas regras consuetudinárias, tendo sido dada nova sistematização e coerência a um corpo mais ou menos uniforme de usos e práticas internacionais, conferindo a esse legado do passado uma precisão de conceitos e uma estruturação por tópicos e matérias, indispensáveis à estabilidade e ao desenvolvimento de relações consulares amistosas entre os países, visando "assegurar o eficaz desempenho das funções das repartições consulares, em nome de seus respectivos Estados", como esclarece o Preâmbulo da Convenção.

Apesar da amplitude e do significado da Convenção de Viena sobre relações consulares, ainda assim permanecem problemas e pontos controvertidos, cuja solução se faz necessária, para que seja possível alcançar níveis mais adequados de relacionamento entre os povos. Os pontos de estrangulamento e os pontos nevrálgicos, contudo, muitas vezes não são decorrentes de limitaçōes dos instrumentos jurídicos e institucionais, mas estão ligados a problemas de outra ordem, cujas sequelas se fazem sentir em detrimento das boas relações entre os povos.

\section{O S.T.F. DECIDE}

O Supremo Tribunal Federal, no desempenho de seu mister, vem se manifestando a respeito de questões envolvendo imunidades diplomáticas e consulares.

A Suprema Corte vem orientando suas decisões em matéria de aplicação de imunidades consulares, em se tratando de cônsules honorários em estrita conformidade com os termos da Convenção de Viena, somente reconhecendo a prerrogativa da imunidade consular, para os atos praticados no exercício das funções consulares.

Em recursos de Habeas Corpus (n- 49183 - São Paulo, publicado na Revista Trimestral de Jurisprudência, vol. 59, pp. 134 a 137), reproduzindo parecer da Procuradoria Geral da República, do qual se transcreve: 
"A Convenção de Viena não confere ao funcionário consular imunidade penal, pois que em seus arts. 41, 42, 63 e 71, prevê a possibilidade de serem eles processados criminalmente, como também submetidos à prisão, em decorrência de sentença judiciária definitiva, valendo ressaltar que a tais funcionários não se estendem as imunidades diplomáticas, mesmo quando, com o consentimento do Estado receptor sejam incumbidos de praticar atos diplomáticos (ver art. 17, parte final).

Preserva tão só a Convenção de Viena, os atos pertinentès às funções consulares, ocorrendo que, se a pretexto de exercê-las, pratica o funcionário ato proibido pelas leis do Estado receptor, descaracteriza-se a função consular, não havendo como negar-se à Justiça desse Estado competência para conhecer do fato, ocorrendo a notitia criminis.

\section{CONCLUSĀO}

Nas mudanças através dos tempos, e na continuidade da presença da instituição consular, vemos o reflexo da necessidade de proteger os cidadãos de determinado Estado durante sua permanência ou sua atuaçāo em outro Estado. Com este fim foram sendo organizadas modalidades de representaçāo cuja funcionalidade foi determinando sua aplicação e sua permanência.

Apesar da organização por parte dos Estados ter tomado a vez a iniciativas de grupos de mercadores e outros profissionais, ainda assim os cônsules honorários, não obstante as mudanças pelas quais passou a instituição, presentes e atuantes no mundo de hoje, ao lado de suas funções enquanto órgãos do Estado que os nomeia, conservam sua qualidade e o prestígio de cidadãos de destaque, cuja atuaçāo se dirige à proteção dos interesses e direitos dos nacionais do grupo em nome do qual ele atua.

A estrita definição das funçōes, de imunidades e privilégios, por meio de convenção internacional, não retira dos cônsules honorários a aura que eles conservam. 